\title{
COMPUTER ANALYSIS OF THE EEG AS AN AID IN THE EVALUATION OF DIETETIC TREATMENT IN PHENYLKETONURIA
}

\author{
D.N.J. DONKER, D. REITS, F.J. VAN SPRANG, W. STORM VAN LEEUWEN and S.K. WADMAN \\ (D.N.J.D. and W.S.v.L) Department of Clinical Neurophysiology, Neurological Clinic University Hospital, \\ Utrecht, (F.J.U.S. and S.K.W.) University Children's Hospital, Het Wilhelmina Kinderziekenhuis, \\ Nieuwe Gracht 137, Utrecht, and (D.R.) Netherlands Ophthalmic Research Institute, \\ Amsterdam (The Netherlands)
}

(Accepted for publication: June 28, 1978)

Phenylketonuria (PKU) can be treated successfully by dietary restriction of phenylalanine. It is generally accepted that treatment should be started as soon as possible after birth. Particularly in the developing brain of newborns and infants the disease nearly always causes serious irreversible damage within a few weeks or months after birth. Disagreement exists, however, about the plasma-phenylalanine level at which treatment with the low phenylalanine diet is necessary. Many American investigators hold that dietetic treatment is not necessary at levels of less than $20 \mathrm{mg} / 100 \mathrm{ml}$ (O'Flynn et al. 1967; Centerwall and Centerwall 1969; Cunningham et al. 1969; Menkes and Aeberhard 1969; Walchner and Kaufman 1970). Other investigators argue, however, that it is still to be proved that disturbances of the cerebral function do not occur at phenylalanine levels between 8 and $20 \mathrm{mg} / 100 \mathrm{ml}$. They are of the opinion that dietetic treatment should be started at levels of more than $8 \mathrm{mg} / 100 \mathrm{ml}$ (Bremer and Neumann 1966; Bickel 1968, 1970; Blaskovics 1974).

Again no common opinion exists concerning the moment at which the dietary treatment can be discontinued. For practical reasons

Correspondence to: D.N.J. Donker, Department of Clinical Neurophysiology, Neurological Clinic University Hospital, Nicolaas Beetsstraat 24, Utrecht, The Netherlands. schoolage, with a wide range, is chosen by many paediatricians. This does not seem to give loss of mental function in general (Beckner et al. 1976). Even termination at the age of 4 years does not seem to result in significantly lower IQs in general (Holtzman et al. 1975). However, toxic symptoms and behavioural changes, and also long term effects such as loss of intellectual performance, following termination have been observed in individual patients (Frankenburg et al. 1973).

From the foregoing it is obvious that there exists a need for an objective method by which the relation between the serum phenylalanine level and the cerebral function can be determined. Disturbances of cerebral function, in so far as there are disturbances of cortical functions or disturbances of corticosubcortical relationships, may be reflected in EEG abnormalities. As reported recently no major changes in EEG patterns were noted after termination of the low phenylalanine diet in 14 early treated patients. Among major changes are understood spike and wave paroxysmal discharges. Minor EEG changes such as low frequency activity were found to occur in $21 \%$ of this group after termination (Rolle-Dayer et al. 1975). EEG changes of this kind lend themselves well to objective evaluation by means of computer analysis.

We therefore started an investigation on the influence of increasing phenylalanine on the EEG of patients suffering from PKU. By 


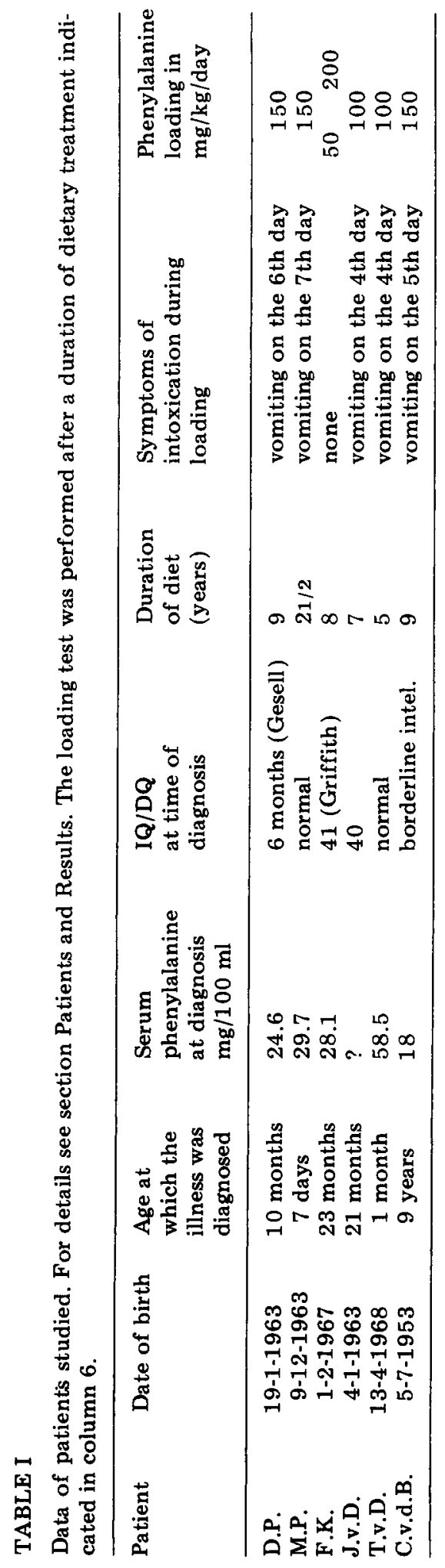


means of spectral analysis we tried to find objective parameters for the relation between the serum phenylalanine level and EEG disturbances.

\section{Patients and methods}

In a preliminary study 6 PKU patients, all on a low phenylalanine diet, were investigated. In 5 of them termination of the diet had to be considered and this opened the possibility to examine the effect of reintroducing phenylalanine on the EEG. The following procedure was pursued.

For a few days the patients were maintained on a low phenylalanine diet and an EEG recording was performed. This first EEG was used as a reference. Then a daily load of 100 or $150 \mathrm{mg}$ L-phenylalanine $/ \mathrm{kg}$ body weight was added to the diet, equally divided over the meals. The loading was continued until obvious clinical or EEG disturbances occurred. During the loading period EEGs were recorded and daily blood samples were taken for the determination of the serum phenylalanine. This was done early in the morning before breakfast. After stopping the loading daily EEG recordings and phenylalanine examinations were continued until the reference values were reached again.

In Table I information about the patients is summarized. Patient F.K. was loaded with 50 $\mathrm{mg} / \mathrm{kg}$; after 20 days $75 \mathrm{mg} / \mathrm{kg}$ was given, after 25 days $100 \mathrm{mg} / \mathrm{kg}$ and after 33 days $200 \mathrm{mg} / \mathrm{kg}$.

\section{Determination of serum phenylalanine}

Serum was deproteinized with solid sulphosalicylic acid, $40 \mathrm{mg} / \mathrm{ml}$. The supernatant $(0.1 \mathrm{ml})$ was applied to the cartridge of a Technicon TSM 1 automated amino acid analyser, provided with an Infotronics CRS$100 \mathrm{~A}$ Integrator and a printer. For the elution of phenylalanine a short program of 57 min (regeneration included) was used. Column: $26 \mathrm{~cm}$, diameter $4 \mathrm{~mm}$; ChromoBeads C3 resin. Buffer: $0.50 \mathrm{~N}$ lithium chlo- ride, $0.05 \mathrm{M}$ citric acid; made to $\mathrm{pH} 3.4$ with $6 \mathrm{~N} \mathrm{HCl}$. Temperature: $63^{\circ} \mathrm{C}$. Flow rate: $0.45 \mathrm{ml} / \mathrm{min}$.

\section{EEG recording and analysis}

Electrodes were fixed to the scalp according to the 10-20 system and the EEGs were recorded by means of a 16-channel EEG apparatus (Elema-Schönander, bandpass $0.3-$ $70 \mathrm{c} / \mathrm{sec}$ ) connected to a 14-channel tape recorder (Ampex).

The EEG records were interpreted visually. In addition, computer analyses were carried out of 8 EEG derivations from $\mathrm{Fp} 2-\mathrm{F} 4$, Fp1-F3, F4-C4, F3-C3, C4-P4, C3-P3, $\mathrm{P} 4-\mathrm{O} 2$ and $\mathrm{P} 3-\mathrm{O} 1$. To this end $100 \mathrm{sec}$ periods free from artefacts were stored on tape and subsequently played back into a digital computer (PDP-15), which was programmed for numerical spectral analysis. Therefore, the signals were subdivided into 50 periods of $2 \mathrm{sec}$, which were analysed according to the Fast Fourier Transform method. The components were measured in a frequency range of $0.5-50 \mathrm{c} / \mathrm{sec}$ with a sample frequency of $128 \mathrm{c} / \mathrm{sec}$. In this way power spectra were obtained. Moreover, coherence functions were computed between the frequencies of symmetrical right and left derivations as well as between anterior and posterior derivations on each side of the head.

\section{Results}

\section{(a) Individual phenylalanine tolerance}

During the phenylalanine loading all patients except one (Table I, F.K.) earlier or later presented clinical symptoms of maldisposition, growing restlessness, verbal agressiveness, increased irritability and finally a short period of sickness and vomiting. These symptoms were accompanied by more or less conspicuous EEG changes.

The clinical and EEG disturbances originated at different serum phenylalanine levels in the different patients. Differences in phenylalanine tolerance existed between the 
subjects investigated, as can be seen from Fig. 1. The peak values of each curve indicate the data at which the clinical or EEG disturbances were so severe that the phenylalanine loading had to be interrupted. The peak levels were different from patient to patient, and were reached after a different number of days. Subject F.K., indicated in the figure with an asterix, finally needed daily phenylalanine doses of $200 \mathrm{mg} / \mathrm{kg}$ body
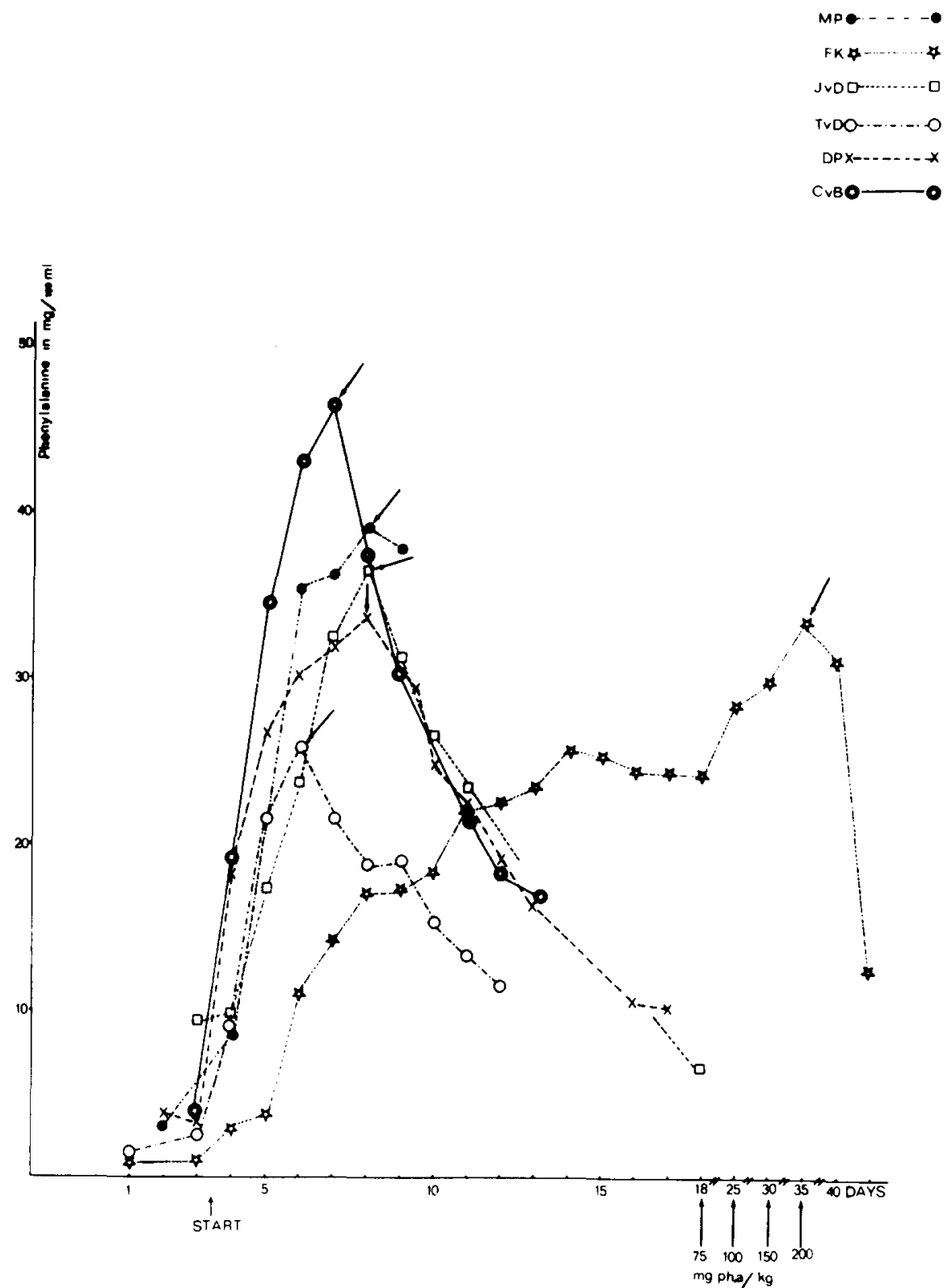

Fig. 1. Relation between fasting serum phenylalanine concentration in $\mathrm{mg} / 100 \mathrm{ml}$ (ordinate) and loading days (abscissa) in 6 children. The loading dose was $100-150 \mathrm{mg}$ phenylalanine $/ \mathrm{kg}$ body weight. Note the rapid decrease of serum phenylalanine concentrations after interruption of the loading. This decrease was correlated with the reversibility of clinical and EEG disturbances. 
weight to present clinical and EEG disturbances. This revealed that the patient had a better tolerance for phenylalanine in his diet than the others, suggesting that the phenylalanine-low diet, which he had used since his second year of life when PKU had been diag-

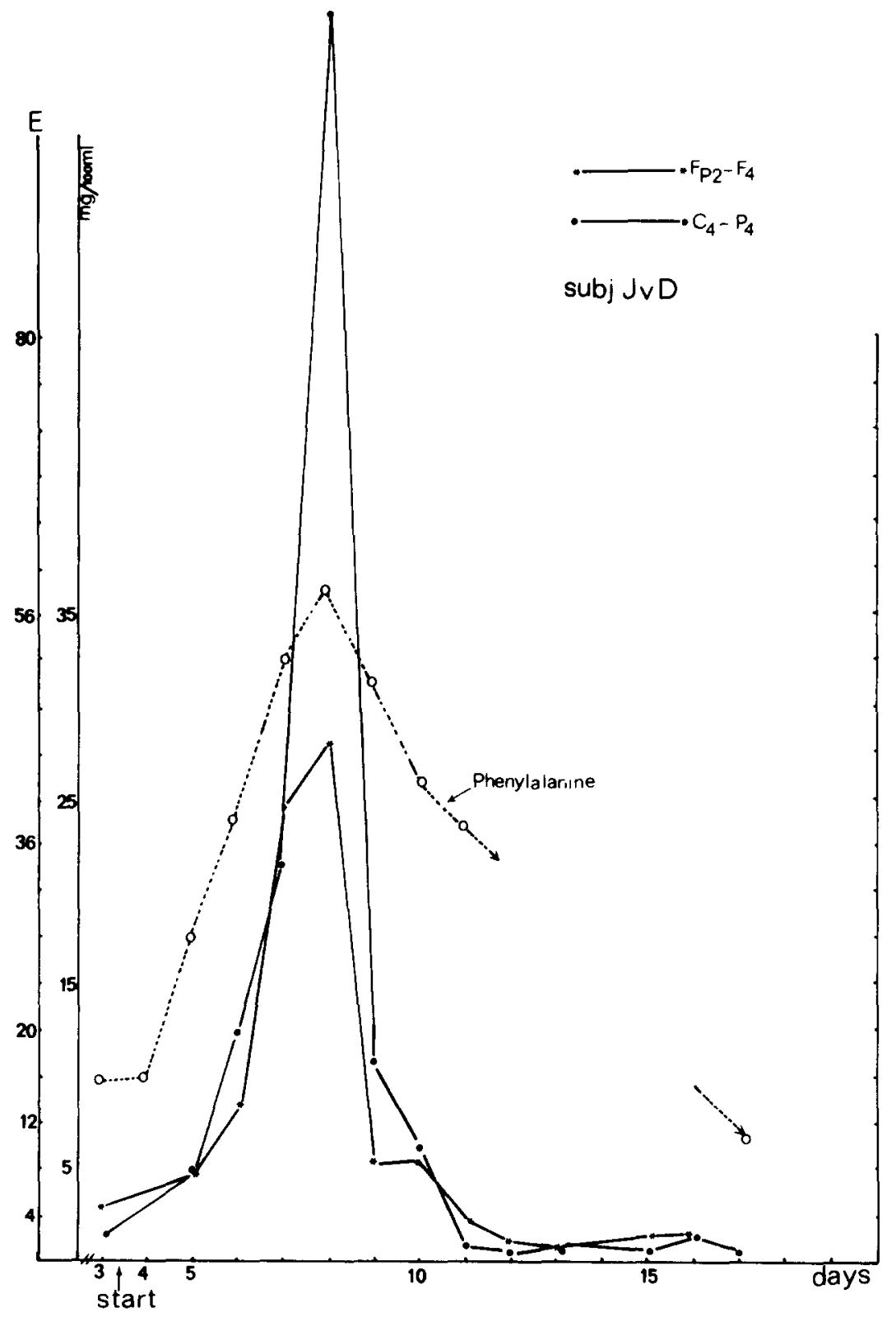

Fig. 2. Relation between serum phenylalanine concentration $(0--0)$ and power $(E)$ in the $2-5$ c/sec frequency band for the frontal $(\mathrm{Fp} 2-\mathrm{F} 4)$ and centroparietal $(\mathrm{C} 4-\mathrm{P} 4)$ derivations on the right side of the skull. On the abscissa the days on which the EEG was recorded are indicated. On the ordinate the power (E) in the $2-5$ c/sec frequency band expressed in $\mu \mathrm{V}^{2}$ per c/sec and the serum phenylalanine concentration in $\mathrm{mg} / 100 \mathrm{ml}$ are shown. Loading starts at day 3 and is discontinued at day 8 . Note the clear increase of $E$, which is most pronounced in the C4-P4 lead, parallel with an increasing phenylalanine level. Subject J.v.D. (Table I). 
nosed, might be discontinued at his present age of 7.5 years.

Fig. 1 also reveals that in all subjects a rapid and clear decrease of serum phenylalanine occurred within the first day after interruption of the loading and that the levels
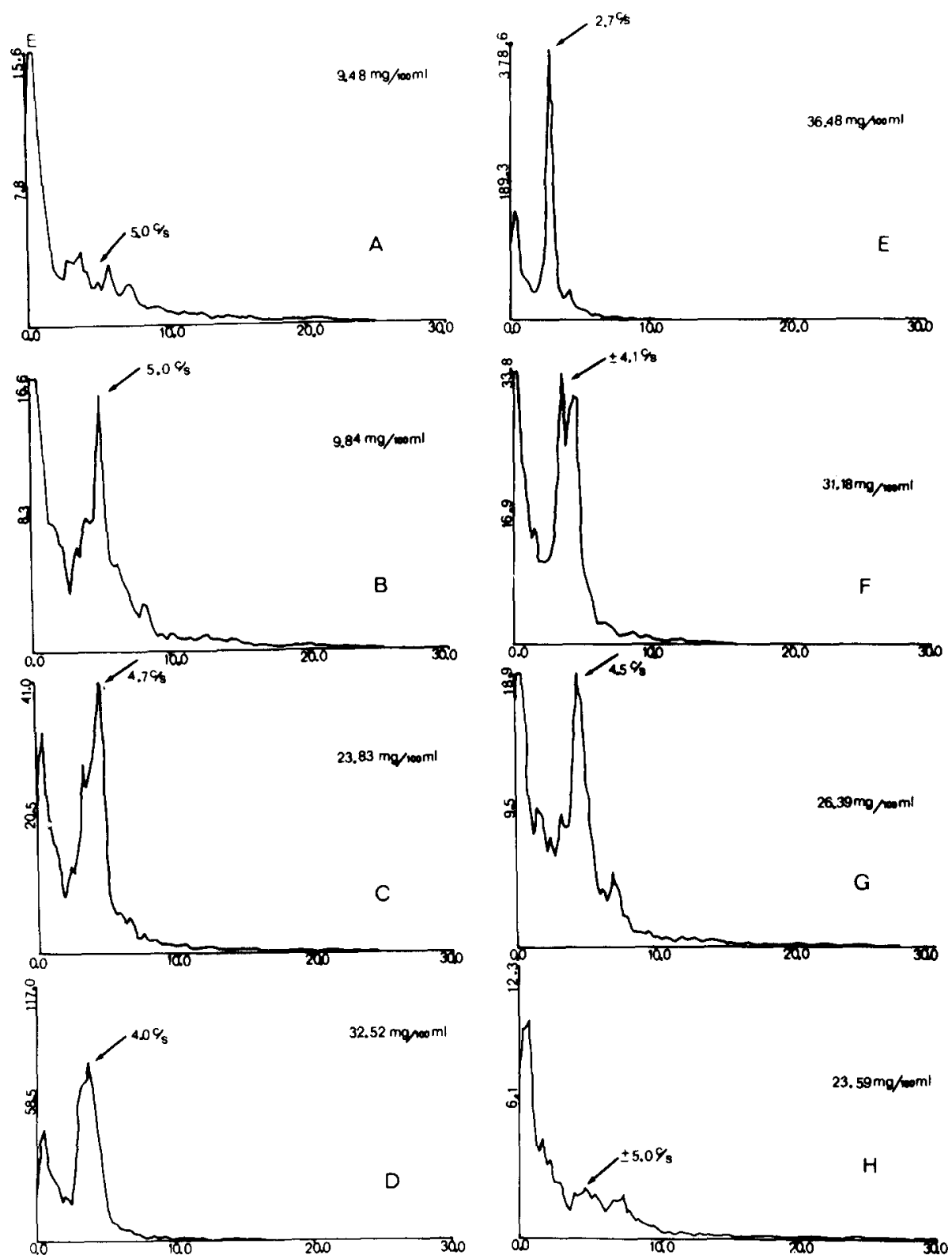

Fig. 3. Relation between serum phenylalanine concentration and frequency peak of power spectrum of the C4-P4 lead. Subject J.v.D. (Table I). On the abscissae the frequency spectra $(0-30 \mathrm{c} / \mathrm{sec})$ are indicated; on the ordinates the power (E) in $\mu V^{2}$ per c/sec. The serum phenylalanine levels at the different loading days are shown in the right top of each figure. The arrows indicate the frequency of the dominant rhythm of the $\mathrm{C} 4-\mathrm{P} 4 \mathrm{deriva-}$ tion. A: day before loading started; B, C, D and E: spectra during loading; F, G and H: after loading stopped. Note shift to the left of the peak frequency during loading. 
returned to normal within 1 week. Clinical symptoms disappeared within a few days and the EEG disturbances reversed.

\section{(b) EEG changes}

When studying the EEG changes caused by the continuous phenylalanine loading 3 aspects can be distinguished: (1) occurrence of activity in the low frequency band (2-5 $\mathrm{c} / \mathrm{sec}) ;(2)$ change in frequency of dominant rhythms (occipital alpha rhythm or central mu rhythm); and (3) change in the degree of synchrony between identical frequencies, occurring in different derivations. The changes were essentially similar in all patients investigated, and therefore a description in some detail in one of them is presented (J.v.D., Table I, Fig. 1).

The first aspect, computed for 2 anteroposterior derivations on the right side of the

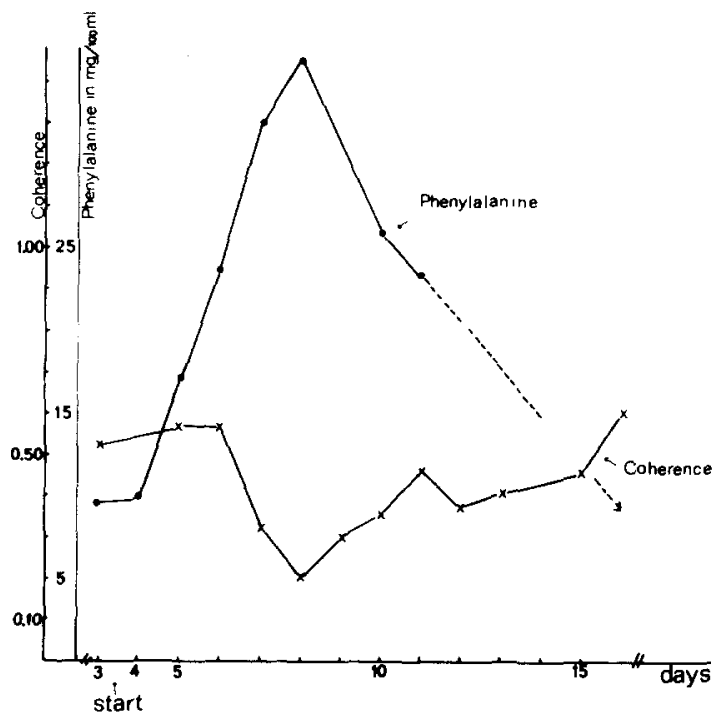

Fig. 4. Relation between serum phenylalanine $(\bullet)$ and right centro-occipital coherence $(x-x)$. Subject J.v.D. (Table I). On the ordinate the serum phenylalanine levels in $\mathrm{mg} / 100 \mathrm{ml}$ are shown as well as the coherence values of the dominant peak in the $2-5 \mathrm{c} / \mathrm{sec}$ frequency band between the right central and the right occipital derivations; on the abscissa the loading days. Note the decrease of the coherence during the increase of the serum phenylalanine concentration. skull, is shown in Fig. 2. It is obvious that in both derivations (Fp2-F4 and C4-P4) the power in the $2-5 \mathrm{c} / \mathrm{sec}$ frequency band increases parallel with the increase of the serum phenylalanine level. The increase is most marked in the centro-parietal lead and least in the frontal lead. This relation was found for all antero-posterior derivations on the right and left sides of the skull.

The second aspect is shown in Fig. 3, which presents the power spectra of $\mathrm{C} 4-\mathrm{P} 4$ on different days of the phenylalanine loading. In these spectra it can be seen that the frequency peak (arrow) presented a shift to the left during the loading days and returned to the starting point after the loading had been stopped. There was a clear relation between this shift to the left of the frequency peak and the rise of the serum phenylalanine. Moreover, it should be remarked that even on the second day of the loading $(3 \mathrm{C})$ a frequency decrease of $0.3 \mathrm{c} / \mathrm{sec}(5.0-4.7)$ took place.

The third aspect is shown in Fig. 4, which presents a clear relation between the coherence of the dominant peak in the 2-5 $\mathrm{c} / \mathrm{sec}$ band and the phenylalanine blood level.

\section{Discussion}

There are many reports in the literature dealing with EEG abnormalities in PKU patients. Abnormalities are frequent in patients without treatment or prior to treatment (Poley and Dummermuth 1968) and mainly normal EEGs are seen in patients treated from an early age (Clayton et al. 1966; Degen et al. 1972). There is no evidence for a pathognomonic EEG abnormality in PKU (Poley and Dummermuth 1968). Loading patients with a single dose of $100 \mathrm{mg}$ L-phenylalanine $/ \mathrm{kg}$ leads to EEG abnormalities only in a number of patients (Clayton et al. 1966; Lässker et al. 1973), but no definite correlation between blood phenylalanine and the presence or absence of EEG changes could be observed (Clayton et al. 1966; Poley and Dummermuth 1968). EEG abnormalities after 
loading have been proposed as a criterion for continuing the dietary therapy in PKU (Clayton et al. 1966; Lässker et al. 1973), but up to the present EEG analysis has not been generally used as a control for termination of the diet.

Clinical observations suggest that PKU produces two effects on the individual: a permanent effect on the developing brain and 'toxic' effects on somatic and central nervous system functions, as pointed out again recently (Anderson et al. 1976). The EEG abnormalities recorded in our study (Figs. 2, 3 and 4) clearly belong to the latter category. They correlated closely with the chemical abnormalities and were reversible. No irritative or epileptic EEG phenomena, such as spikes or spike-and-wave complexes, were seen in the EEGs of our patients. EEG disturbances of this kind, occurring with or without clinical symptoms of epilepsy, are not influenced by dietetic or anti-epileptic treatment. At present it is not known whether and to what extent changes of frequencies of dominant rhythms reflect brain damage. On the basis of general knowledge we assume that frequency changes of $1 \mathrm{c} / \mathrm{sec}$ of the dominant rhythms can be tolerated. As stated in the Introduction, most investigators are of the opinion that at phenylalanine levels of $20 \mathrm{mg} /$ $100 \mathrm{ml}$ and higher, brain damage will occur. In our patients the EEG changes were considerable at this level, but still reversible.

The changes may be observed by visual inspection of the EEG, but computer analysis may reveal subtle EEG changes that are not detected by visual inspection, for example the shift of $0.3 \mathrm{c} / \mathrm{sec}$ during the first day of the loading test shown in Fig. 3B and C. Computer analysis, moreover, produces quantitative data by means of which the day-to-day changes can be evaluated properly. It should be stressed here that the beginning of the EEG changes during loading preceded the occurrence of the behavioural changes observed by the nurses who supervised the patients, demonstrating that the method is highly sensitive.
The results of our investigations in a small group of 6 patients are illustrative of the way that the EEG parameters obtained can be used. One child (F.K., Fig. 1) had a rather good tolerance for dietary phenylalanine biochemically as well as electroencephalographically. As a consequence of these results he was taken off diet. The oldest child of our group (C.v.d.B., Fig. 1), however, presented a low phenylalanine tolerance, indicating that his diet should not be stopped. In the other 4 children the diet was continued; this was based on the EEG alterations appearing at high phenylalanine levels. However, the usefulness of our method has still to be demonstrated in a larger group of patients.

After the first encouraging results we think that the EEG data obtained with our method may be useful for the termination of the diet in PKU. It seems possible to assess whether a patient can tolerate a normal amount of phenylalanine. Furthermore, it seems possible to determine for each individual patient the optimal amount of protein (phenylalanine) which does not produce intoxication, by increasing the dietary protein gradually under control of the EEG.

\section{Summary}

The effect on the EEG of the reintroduction of phenylalanine in the diet of 6 patients with PKU on treatment was studied. Patients received daily loads of 100 or $150 \mathrm{mg}$ L-phenylalanine $/ \mathrm{kg}$, equally divided over the meals, and computerized spectral EEG analysis was performed. The following EEG changes were seen: (1) occurrence of activity in the low frequency band $(2-5 \mathrm{c} / \mathrm{sec}),(2)$ change of frequency of dominant rhythms; (3) change in the degree of synchrony between identical frequencies, occurring in different derivations. EEG changes increased quantitatively parallel to increasing blood phenylalanine and reversed after stopping the phenylalanine administration, suggesting that the EEG abnormalities are a measure for the 
degree of intoxication caused by phenylalanine or its metabolites. It is suggested that the EEG data may be useful in deciding to terminate the diet in PKU.

\section{Résumé}

Utilité de l'analyse quantitative de l'EEG dans le traitement diététique de la phénylcétonurie

On étudie l'effet, sur l'EEG, d'une réintroduction de phénylalanine dans l'alimentation de 6 patients atteints de phénylcétonurie et traités. Les patients recevaient quotidiennement 100-150 mg de L-phénylalanine $/ \mathrm{kg}$, également repartis entre les repas. Une analyse spectrale de l'EEG, effectuée dans ces conditions, a revélé les modifications suivantes: (1) apparition d'une activité dans la bande des fréquences basses $(2-5 \mathrm{c} / \mathrm{sec}) ;(2)$ modification de la fréquence des rythmes dominants; (3) changement dans le degré de simultanéité d'apparition de fréquences identiques sur différentes dérivations. Ces modifications de l'EEG s'accentuèrent (quantitativement) en même temps qu'augmentait le taux sanguin de phénylalanine, et diminuèrent après arrêt du traitement; ce qui suggère que les altérations EEG constituent une mesure du degré d'intoxication par la phénylalanine ou ses métabolites. Les données EEG paraissent donc utile dans une décision d'arrêter un régime en cas de phénylcétonurie.

\section{References}

Anderson, V.E., Siegel, F.S. and Bruhl, H.H. Behavioural and biochemical correlates of diet change in phenylketonuria. Pediat. Res., 1976, 10: 10-17.

Beckner, A.A., Centerwall, W.R. and Holt, W. Effects of rapid increase of phenylalanine intake in older PKU children. J. Amer. diet. Ass., 1976, 69: 148151.

Bickel, H. A clinician's approach to the differentiation and management of the various forms of hyperphenylalanine. In: Proc. 1st Congr. Int. Ass. Scient. Study of Mental Def. Montpellier Jackson Publish. Co, England, 1968.

Bickel, H. Recent advances in the early detection and treatment of inborn errors with brain damage. Neuropädiatrie, $1970,1: 379-382$.

Blaskovics, M.E., Schaeffer, G.E. and Hack, Sh. Phenylalaninemia. Differential diagnosis. Arch. Dis. Child., 1974, 49: 835-843.

Bremer, H.J. und Neumann, W. Phenylalanintoleranz bei Frühgeborenen, reifen Neugeborenen, Säuglingen und Erwachsenen. Klin. Wschr., 1966, 44: 1076-1081.

Centerwall, S.A. and Centerwall, W.R. Phenylketonuria and phenylalanine diet. J. Pediat., 1969, 74 : 1008-1009.

Clayton, B.E., Moncrieff, A.A., Pampiglione, G. and Shepherd, J. Biochemical and EEG studies in phenylketonuric children during phenylalanine tolerance tests. Arch. Dis. Child., 1966, 41:267272.

Cunningham, G.C., Day, R.W., Berman, J.L. and Hsia, D.Y.Y. Phenylalanine tolerance tests. Amer. J. Dis. Child, , 1969, 117: 626-636.

Degen, R., Lässker, G. und Theile, H. Befunde bei Phenylketonurie. Kinderärztl. Praxis, 1972, 40: 97-107.

Frankenburg, W.K., Goldman, A.D. and Olson, C.O. Behavioral consequences of increased phenylalanine intake in phenylketonuric children: a pilot study describing a methodology. Amer. J. ment. Defic., 1973, $77: 524-532$.

Holtzman, N.A., Welcher, D.W. and Mellits, E.D. Termination of restricted diet in children with phenylketonuria: a randomized controlled study. New Engl. J. Med., 1975, 293: 1121-1124.

Lässker, G., Degen, R. und Theile, H. Das Electroencephalogramm als Kriterium für die Beendigung der diätetischen Behandlung des Phenylketonurie? Pädiat. Pädol., 1973, 8: 187-194.

Menkes, J.H. and Aeberhard, E. Maternal phenylketonuria. J. Pediat., 1969, 74: 924-932.

O'Flynn, M.E., Tillman, P. and Hsia, D.Y.Y. Hyperphenylalaninemia without phenylketonuria. Amer. J. Dis. Child., 1967, 113: 22-30.

Poley, J.R. and Dummermuth, G. EEG findings in patients with PKU. In: K.S. Holt and V.P. Coffey (Eds.), Some Recent Advances in Inborn Errors of Metabolism. Livingstone, Edinburgh, 1968: 61-79.

Rolle-Dayer, H., Pueschel, S.M. and Lombroso, C.T. Electroencephalographic findings in children with phenylketonuria. Amer. J. Dis. Child., 1975, 129 : 896-900.

Walchner, A.M. and Kaufman, R.L. Phenylketonuria, diagnostic and therapeutic dilemma. Clin. Pediat., 1970, 9: 263-269. 